\title{
Biodegradability of Acinetobacter junii CNI PHB Copolymerized with PHV
}

\author{
Kasthuri, J. ${ }^{1}$, Poornima, S. ${ }^{2}$ \\ ${ }^{1,2}$ Department of Zoology, The Standard Fireworks Rajaratnam College for Women, Sivakasi - 626 123, Tamil Nadu, India
}

\begin{abstract}
Acinetobacter junii CN1 PHB, copolymerized with commercial (Sigma) PHV (1:1 ratio) when subjected to soil burial assay exhibited complete degradation on $60^{\text {th }}$ day. The structural changes occurred in PHBV were then analyzed with AFM, IR spectral readings and TEM as well. A total of 6 PHBV degrading bacterial strains (S1-S6) were isolated not only from the soil in which the PHBV was buried but also from the surface of the degraded PHBV membrane. The isolates were then identified based on their morphological and biochemical characteristics. Further, on screening the six bacterial isolates of the present study, for their PHBV degrading potential, the maximum clear zone was reported with A. faecalis. It is believed that the extracellular PHB depolymerases of the bacterial isolate would serve as the principal enzyme in degradation of $\mathrm{PHB}$ / oligomers into dimmers or monomers. These low molecular weight fragments would be further utilized by the microbes as sole carbon and energy sources.
\end{abstract}

Keywords: Acinetobacter junii CN1 PHB, copolymerization, PHBV, biodegradability

\section{Introduction}

PHB, a fascinating homopolymer, is existing as a highly crystalline and stiff material. It has also been characterized with poor elastic properties [10]. It can be made better with improved physical and mechanical properties by blending / copolymerization with $5 \%$ valerate [2]. In general, copolymerization enables the polymers to become more flexible and tougher than PHB. Further, they do facilitate easier degradation when discharged into natural environment [28]. Besides, the spectrum of possible applications also expands with the modified physical properties of the polymer blends. It is worth mentioning that the microbial PHB which could copolymerize with 5, 8 and $12 \%$ HV contents are proved to be suitable for tissue engineering [ 5] , [25 ].

In general PHB, PHBV and other PHAs are being utilized by the microorganisms as energy sources and degraded in microbial active environments [14], [22], [23]. The first report on the function of PHB has been explained in 1958 which demonstrate the rapid biodegradability of PHB produced by B.megaterium and B.cereus [12]. Biodegradation of PHB under aerobic conditions results in $\mathrm{CO}_{2}$ and $\mathrm{H}_{2} \mathrm{O}$. Whereas, in anaerobic conditons, the degradative products include $\mathrm{CO}_{2}$ and $\mathrm{CH}_{4}$.

The biodegradability of the biopolymer may depend upon the polymer characteristics, organism type and nature of pretreatment [27]. The pre-treatment of polyethylene is very significant for its biodegradation. Physical rupturing of the polyethylene and chemical washing by ethanol might have added value to its degradability. Supportingly, the improved biodegradation rate of the polymer has been reported with fungal cultures containing polyethylene added with ethanol [29]. However, the fate of these organic polymers in the environment and the time required for their complete mineralization into $\mathrm{CO}_{2}$ needs to be fully understood [26].

As the microbial degradation of PHAs can take place in natural environments especially in soil, [9] where it is being dumped largely at landfills, the present investigation attempts to degrade the Acinetobacter junii CN1 PHB copolymerized with PHV, by subjecting to soil burial assay.

\section{Materials and Methods}

\subsection{Copolymerization}

The PHB extracted from Acinetobacter junii CN1 [24] was copolymerized with commercial poly -hydroxy valeric acid (Sigma) (1:1 ratio) by dissolving in $5 \mathrm{ml}$ chloroform and fabricated into a film by casting in clean, dry, glass Petri dish in a fume hood [31]. The film was further dried for 24 hrs. The dry copolymerized PHBV film was then removed from the Petri dish using a razor blade and subjected to physical and molecular characterizations.

\subsection{Biodegradation of Copolymerized PHBV in Garden Soil}

Biodegradability of the copolymerized PHBV was determined by subjecting the sample for soil burial assay [3]. Accordingly, the copolymerized PHBV film was buried in garden soil collected in a large plastic tray maintained at room temperature for a period of 2 months. The structural changes occurred in the polymer were then analyzed with AFM (XE-70, Park System, Korea), IR (Schimadzu - IR Tracer 100, Japan) spectral readings and TEM (Leica SP2, Japan) analysis as well.

\subsection{Isolation of Copolymerized PHBV Degrading Microorganisms}

The soil sample used in biodegradation assay was serially diluted. From $10^{-6}$ dilution, $0.1 \mathrm{ml}$ was taken and inoculated in a sterilized plate with mineral salt medium containing PHBV which was fabricated with the extracted PHB obtained on sonication (Sonication for 2 hrs at 90 duty cycles) and commercial PHV (glucose substitute) in 1: 1 ratio. The plates were then incubated at $37^{\circ} \mathrm{C}$ for $72 \mathrm{hrs}$. The isolates which produced the maximum zone of clearance [3] were then subjected not only tomorphological and 
biochemical characterizations but also to molecular characterization by $16 \mathrm{~S}$ rRNA sequencing.

\section{Results and Discussion}

\subsection{Copolymerized PHBV}

The copolymerized PHBV of the present study (Plate 1), was characterized with Atomic Force Microscope. It is a powerful tool to observe the

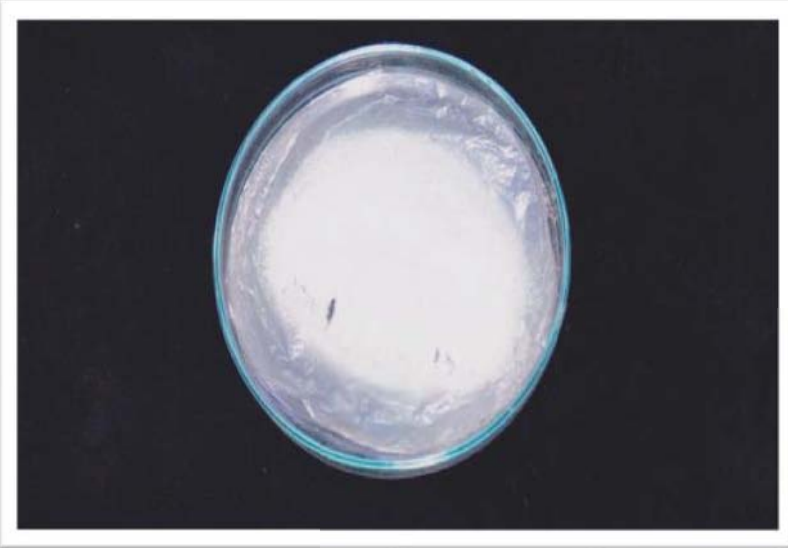

Plate 1: Copolymerized PHBV

thickness of the membrane. While screening the topography of PHBV under AFM, it revealed $2-5 \mu \mathrm{m}$ thickness and $79.219 \mathrm{~nm}$ roughness (Plate 2 \& 3; Table 1). It is noteworthy, that the roughness seemed to be increased with the degradation of the biopolymer [31].

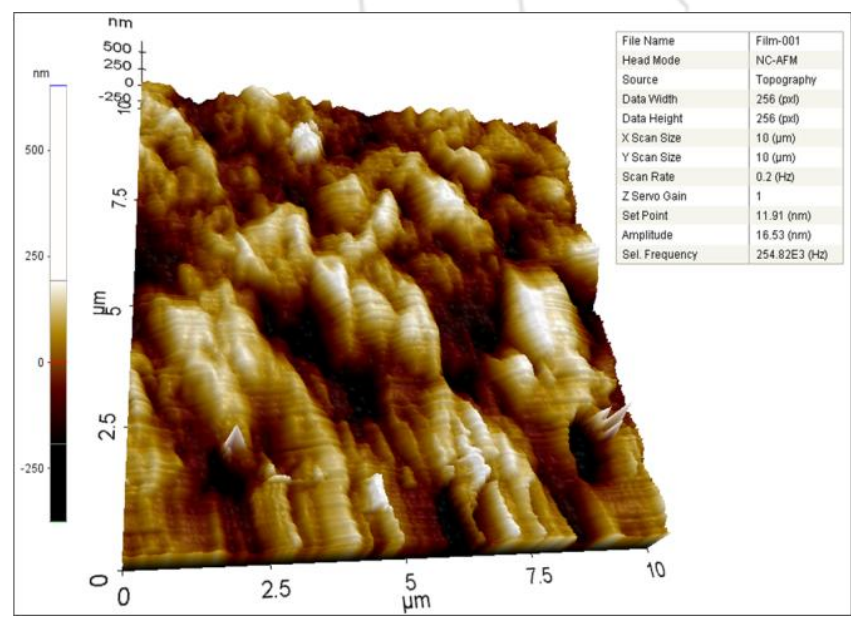

Plate 2: AFM image of copolymerized PHBV measuring thickness

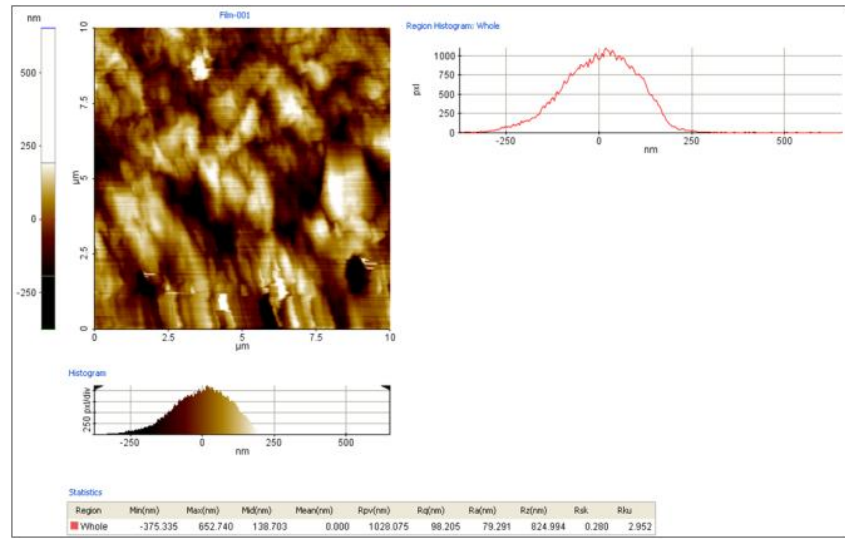

Plate 3: AFM image of copolymerized PHBV measuring roughness

Table 1: Physical characterization of PHBV with AFM

\begin{tabular}{|c|c|}
\hline Physical Properties & Measurement \\
\hline Thickness & $2-5 \mu \mathrm{m}$ \\
\hline Roughness & $79.291 \mathrm{~nm}$ \\
\hline
\end{tabular}

\subsection{Biodegraded Copolymerized PHBV in Garden Soil}

Initially, on visual observation, the PHBV film degraded in soil by a fortnight, revealed tiny holes, tear or thinning out of the film and some cracks in certain areas. Subsequently, the similar trend has also been reported [32]. The wide visible changes observed on polymer degradation, includes roughness of the surface, formation of holes or cracks, defragmentation, changes in colour and /or formation of biofilms on the surface [8]. These visual changes can be used as a first indication of microbial attack.

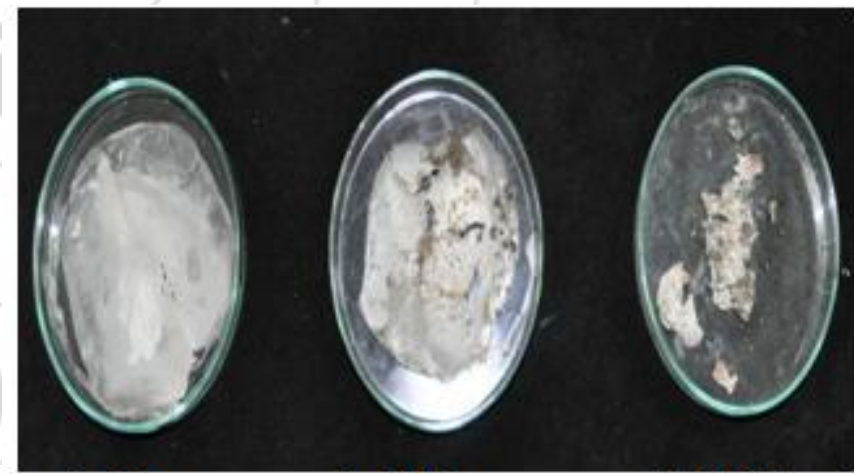

A. 0 Day

B. $15^{\text {th }}$ Day

C. $60^{\text {th }}$ Day

Plate 4: PHBV subjected to soil burial assay

Further, the chemical changes due to the microbial activity in the course of biodegradation studies of polymer can also be assessed with FTIR techniques [16]. On soil burial assay, the remarkable changes were reported on $60^{\text {th }}$ day and the IR spectrum revealed the peaks at 3424.73, 2928.04 , 1722.49, 1632.80, 1383.97, 1280.78, 1099.46 and $1035.81 \mathrm{~cm}^{-}$ ${ }^{1}$ (Plate 4 - 6; Figure 1 \& 2). 


\section{International Journal of Science and Research (IJSR)}

ISSN (Online): 2319-7064

Index Copernicus Value (2013): 6.14 | Impact Factor (2014): 5.611

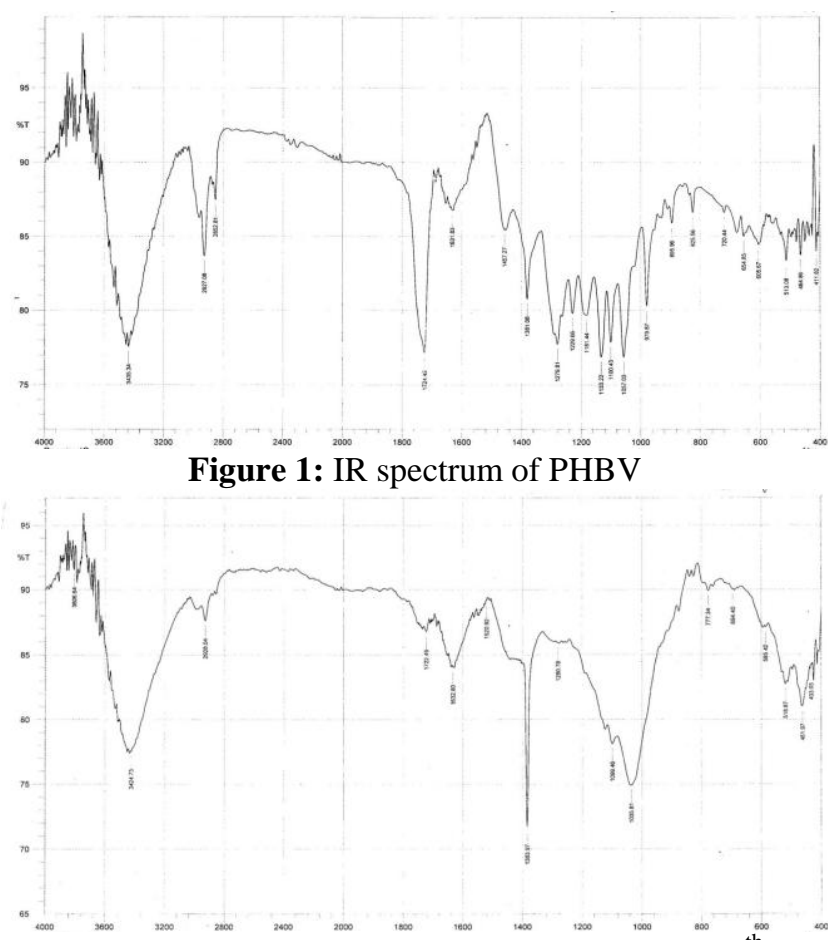

Figure 2: IR spectrum of soil degraded PHBV on $60^{\text {th }}$ day

Further, the results of the TEM analysis of the PHBV subjected to soil burial assay (Plate 7) had revealed a rapid reduction in thickness from $2 \mu \mathrm{m}$ to $1 \mu \mathrm{m}$ on $15^{\text {th }}$ day, 1 $\mu \mathrm{m}-0.5 \mu \mathrm{m}$ on $30^{\text {th }}$ day and $0.5-0.2 \mu \mathrm{m}$ on $60^{\text {th }}$ day. On an observation under TEM for the morphological changes occurred in the thin PHB film on enzymatic degradation, both the surface $(4-5 \mathrm{~nm})$ and lamellar crystal $(8-10 \mathrm{~nm})$ were reported to exhibit reduction in thickness. This would suggest the possibility of preferential hydrolyses of the crystals by PHB depolymerase. The biodegradation of different commercial biopolymers at moderate temperature in different soil types with $30 \%$ weight loss after 3 months period has also been demonstrated [17].

Consequently, several authors [20], [6], [7] , [30] have also observed the complete degradation of PHBV on 6, 7 and 350 weeks in sewage, soil and sea water respectively.

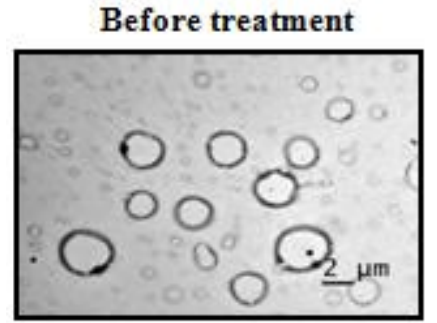

After $\mathbf{3 0}$ days

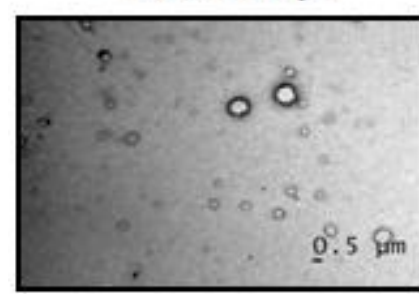

Plate 5: TEM image of PHBV degraded in soil revealing the thickness

\subsection{PHBV Degrading Microorganisms}

In the present study, a total of 6 PHBV degrading bacterial strains (S1- S6) were isolated not only from the soil in which the PHBV was buried but also from the surface of the degraded PHBV membrane. The isolates were then identified based on their morphological and biochemical characteristics (Table 2).

With the results of the morphological and biochemical characterizations, the PHBV degrading bacterial strains S1, S2, S3, S4, S5 and S6 of the present investigation were identified as Bacillus, Bifidobacterium1 , Bifidobacterium 2, Corneybacterium, Bifidobacterium 3 and Alcaligenes faecalis respectively (Table 2).

In this context, the bacterial isolates viz., Pseudomonas (both fluorescent \& non-fluorescent forms), Bacillus, Azospirillum, Mycobacterium and Streptomyces have been detected over the degraded PHB films [4]. Besides, it has been observed that the fungal isolates exhibit much higher capabilities than the bacteria in degrading PHAs [11].

Further, on screening the six bacterial isolates of the present study, for their PHBV degrading potential, the maximum clear zone was reported with $A$. faecalis (Plate 6). The similar zones of

clearance have been reported around the colony [3]. This is mainly due to the hydrolysis of the suspended polyesters by the target organism. 


\section{International Journal of Science and Research (IJSR) \\ ISSN (Online): 2319-7064 \\ Index Copernicus Value (2013): 6.14 | Impact Factor (2014): 5.611}

Table 2: Morphological and biochemical characteristics of PHBV degrading bacteria

\begin{tabular}{|c|c|c|c|c|c|c|}
\hline \multirow[t]{2}{*}{ Characterization } & \multicolumn{6}{|c|}{ Inference } \\
\hline & S1 & S2 & S3 & S4 & S5 & S6 \\
\hline Gram reaction & + & + & + & + & + & + \\
\hline Shape & Rod & Rod & Rod & Rod & Rod & Rod \\
\hline Motility & Jon motile & Non motile & Non motile & Non motile & Non motile & Non motile \\
\hline Colony morphology & $\begin{array}{l}\text { White } \\
\text { irregular } \\
\text { colonies }\end{array}$ & $\begin{array}{c}\text { Light } \\
\text { white, smooth, } \\
\text { flat, irregular }\end{array}$ & $\begin{array}{c}\text { Light cream, } \\
\text { smooth, flat, } \\
\text { irregular }\end{array}$ & $\begin{array}{c}\text { Dull white } \\
\text { small, flat, } \\
\text { circular }\end{array}$ & $\begin{array}{l}\text { Light cream, } \\
\text { smooth, } \\
\text { flat, irregular }\end{array}$ & $\begin{array}{c}\text { Light cream, } \\
\text { smooth, flat, } \\
\text { irregular }\end{array}$ \\
\hline Indole test & - & - & - & - & - & - \\
\hline Methyl red test & + & + & + & + & + & + \\
\hline Voges- proskauer test & + & - & - & - & - & - \\
\hline Citrate test & + & - & - & + & - & - \\
\hline Catalase test & - & - & - & + & - & - \\
\hline Oxidase test & + & - & - & - & - & - \\
\hline Triple- sugar iron agar test & + & + & + & + & + & + \\
\hline Urease test & + & + & + & + & + & + \\
\hline Gelatin hydrolysis test & + & + & + & + & - & + \\
\hline Probable identification & Bacillus & $\begin{array}{c}\text { Bifido } \\
\text { bacterium } 1\end{array}$ & $\begin{array}{c}\text { Bifido } \\
\text { bacterium } 2 \\
\end{array}$ & $\begin{array}{c}\text { Corney } \\
\text { bacterium }\end{array}$ & $\begin{array}{c}\text { Bifido } \\
\text { bacterium } 3\end{array}$ & $\begin{array}{c}\text { Alcaligenes } \\
\text { faecalis }\end{array}$ \\
\hline
\end{tabular}

The clear zone test gives an opaque appearance in the polymer coated medium. The formation of a clear halo around the colony also indicates the first step of degradation and reveals the degradability of the microorganism [21], [1]. Further, the semi quantitative results can also be obtained by analyzing the growth of clear zones [3].

It is believed that the principal enzyme pertaining to the degradation of PHB / oligomers is PHB depolymerase. The extracellular PHB depolymerases are being isolated from different bacteria viz., A. faecalis, $R$. rubrum, B. megaterium, A.beijerinckii and $P$. lemoignei. Besides, polyhydroxyalkanoic acid degrading fungi have also been isolated from various environments such as freshwater, sea water and sludge sample [15]. It has been established that many fungal taxa belonging to Basidiomycotina, Denteromycotina and Ascomycotina are the predominant degraders of PHAs in natural environment [19] .

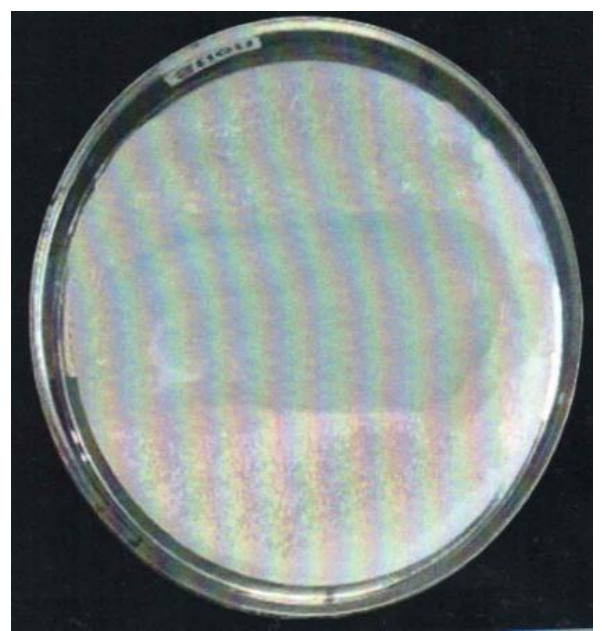

Plate 6: Zone of clearance exhibited by PHBV degrading A.faecalis

By 1992, Aspergillus has been reported as one of the predominant genera involved in PHB degradation [13]. In addition to Aspergillus, a number of other mesophilic fungi belonging to the genera Penicillium and Paecilomyces are found to be responsible for degrading PHAs in soil and aquatic environments [11].

PHAs degrading organisms, at once when get attached to the surface of the polymer they get started to grow by exploiting them (PHAs) as the carbon source. In the primary degradation, the cleavage of the main chain leads to the formation of dimmers or monomers. These low molecular weight fragments are further utilized by the microbes as sole carbon and energy sources [28].

The resultant breakdown fragments must be completely used by the microorganisms, otherwise the remnants would cause brutal environmental and health hazards [18]. However, the biodegradability of biopolymer depends primarily on its molecular weight, molecular structure and crystallinity as well. Nevertheless, the degradability decreases with the increase in molecular weight.

\section{Acknowledgement}

The Authors gratefully acknowledge the Ministry of Environment and Forestry, Govt. of India, New Delhi for the financial assistance and the Management SFR College for Women for having extended the infrastructure.

\section{References}

[1] D.M. Abou-Zeid, R.J. Muller, and W.D. Deckwer, Degradation of natural and synthetic polyesters under anaerobic conditions, Journal of Biotechnology, 86, pp. 113-126, 2001.

[2] I.S. Aldor, and J.D. Keasling, Process design for microbial plastic factories: metabolic engineering of polyhydroxyalkanoates, Current Opinion in Biotechnology, 14 , pp. 475-483, 2003.

[3] J. Augusta, R.J. Muller, and H. Widdecke, A rapid evaluation plate-test for the biodegradability of plastics, Applied Microbiology and Biotechnology, 39, pp. 673678, 1993. 


\section{International Journal of Science and Research (IJSR) \\ ISSN (Online): 2319-7064}

Index Copernicus Value (2013): 6.14 | Impact Factor (2014): 5.611

[4] A.P. Bonartsev, V.L. Myshkina, D.A. Nikolaeva, E.K.Furina, T.A. Makhina, A.P.B. Livshits, E.A. Ivanov, A.L. Iordanskii, and G.A. Bonartseva, Biosynthesis, biodegradation and application of poly(3hydroxybutyrate) and its copolymers-natural polyesters produced by diazotrophic bacteria, Current Research and Education Topics and Trends in Applied Microbiology, 1 , pp. 295-307, 2007.

[5] C. Doyle, E.T. Tanner, and W. Bonfield, In vitro and in vivo evaluation of polyhydroxybutyrate and of polyhydroxy butyrate reinforced with hydroxyapatite, Biomaterials, 12 , pp. 841-847, 1991.

[6] Y. Gao, L. Kong, L. Zhang, Y.D. Gong, G.Q. Chen, N.M. Zhao, and X.F. Zhang, 2006, Improvement of mechanical properties of poly(DL-lactide) films by blending of poly( 3-hydroxybutyrate-co-3 hydroxy hexanoate), European Polymer Journal , 42 , pp. 764775.

[7] B. Hazer, and A. Steinbüchel, Increased diversification of polyhydroxyalkanoates by modification reactions for industrial and medical applications, Applied Microbiology and Biotechnology, 74 , pp.1-12, 2007.

[8] E. Ikada, Electron microscopic observation of biodegradation of polymers, Journal of Environmental Polymer Degradation, 7 , pp. 197-201, 1999.

[9] D. Jendrossek, A. Schirmer, and H.G. Schlegel, Biodegradation of polyhydroxy alkanoic acid, Applied Microbiology and Biotechnology, 46 , pp. 451-463, 1996.

[10] L. Kashma, Studies on the production of biopolymers by Rhizobium Sp. their isolation and characterization, $\mathrm{PhD}$ Thesis, University of Mysore, Mysore, 2004.

[11]D.Y. Kim, and Y.H. Rhee, Biodegradation of microbial and synthetic polyesters by fungi, Applied Microbial Biotechnology, 61, pp. 300 - 308, 2003.

[12] R.M. Macrae and J.F. Wilkinson, Poly $\beta$ - hyroxybutyrate metabolism in washed suspensions of Bacillus cereus and Bacillus megaterium, Journal of General Microbiology, 19 , pp. 210-222, 1958.

[13] M. Matavuli, and H.P. Molitoris, Fungal degradation of poly- $\beta$ - hydroxyl alkanoates (PHA) and a semi quantitative assay for screening their degradation by terrestrial fungi, FEMS Microbiological Review, 103 , pp. 323-332, 1992.

[14] J. Mergaert, A. Wouters, and J. Swing, Estimation of the intrinsic biodiversity among poly (3- hydroxyalkanoates) degrading Streptomyces using gas chromatographic analysis of fatty acids, Systematic Applied Microbiology, 17, pp. 601-612, 1994.

[15] J.A. Mergaert, L. Schimer, M. Hauben, D. Mau, D. Jendrossek, and J. Swing, Isolation and identification of poly (3-hydroxy valerate) degrading strains of Pseudomonas lemoignei, International Journal of Systematic Bacteriology, 46 , pp. 769- 773, 1996.

[16]O. Milstein, A. Huttermann, R. Freud, and H. Leudemann, Enzymatic co-polymerization of lignin with low-molecular mass compounds, Applied Microbiology and Biotechnology, 40 , pp. 760 - 768, 1994.

[17]H.M. Mostafa, H. Sourell, and F.J. Bockisch, The mechanical properties of some bioplastics under different soil types for use as a biodegradable drip tubes, CIGR E Journal, 12 , pp. 12 -21, 2010.
[18]B. Narayan, Biobased and biodegradable polymer materials, rationale, drivers and technology exemplers. American Society for Symposium, 939 , pp. 282, 2006.

[19] S.Neumeier, Abbu thermoplastischer biopolymerre auf poly- $\beta$ - hydroxyalkanoates basic durch terrestrische and marine pilze, Diplomarbeit, Botanical Institute University, Reyensburg, 1994.

[20] H.Nishida, and Y. Tokiwa, Effects of higher-orderstructure of poly(3- hydroxybutyrate) on its biodegradation. II. Effects of crystal structure on microbial degradation, Journal of Environmental Polymer Degradation , 1, pp. 65 - 80, 1993.

[21] Noda, P.R. Green, M.M. Satkowski, and L.A. Schechtman, Preparation and properties of a novel class of polyhydroxyalkanoate copolymers, Biomacromolecules, 6 , pp. 580 - 586, 2005.

[22] L.A. Petrasovits, M.P. Purnell, L.K. Nielsen, and S.M. Brumbley, Production of polyhydroxybutyrate in sugarcane, Plant Biotechnology Journal, 5 , pp. 162-172, 2007.

[23] M. Pijuan, C. Casas, and J.A. Baeza, Polyhydroxyalkanoate synthesis using different carbon sources by two enhanced biological phosphorus removal microbial communities, Process Biochemistry, 44, pp. 97-105, 2009.

[24]S. Poornima, Production, Optimization and Characterization of PHB of Acinetobacter junii CN1 Strain an Isolate of Agro-industrial Site, PhD Thesis, Madurai Kamaraj University, Madurai, 2016.

[25] D. Sendil, I. Gürsel, D. L. Wise, and V. Hasirci, Antibiotic release from biodegradable PHBV micro particles, Journal of Controlled Release, 59 , pp. $207-$ 217, 1999.

[26] H.A. Shafei, N.H.A. Nasser, A.L. Kansoh, and A.M. Ali, Biodegradation of disposable polyethylene by fungi and Streptomyces species, Polymer Degradation and Stability, 62 , pp. 361-365, 1998.

[27] A.A. Shah, F. Hasan, A. Hameed, and S. Hameed, Biological degradation of plastics : A comprehensive review, Biotechnology Advances, 26 , pp. 246 -265, 2008.

[28] C.Vasile, Degradation and decomposition, In: Handbook of polyolefins synthesis and properties edited by C. Vasile and R.B.Seymour, (Marcel Dekker Inc, New York), pp. 479 - 509, 1993.

[29] T. Volke-Sepulveda, G. Saucedo-Castaneda, M. Gutierrez-Rojas, A. Manzur, and E. Favela-Torres, Thermally treated low density polyethylene biodegradation by Penicillium pinophilum and Aspergillus niger, Journal of Applied Polymer Science, 83 , pp.305 - 314, 2002.

[30]I.Vorman, and L. Tighzert, 2009, Biodegradable Polymers, Materials, 7 , pp. 335 -344.

[31] C.A. Woolnough, T. Charlton, L.H. Yee, M. Sarris, and L.J.R. Foster, Surface changes in polyhydroxyalkanoate film during biodegradation and biofouling, Polymer International , 57 , pp. 1042-1051, 2008.

[32] K. Yamamoto - Tamura, S. Hiradate, T. Watanabe, M. Koilbabashi, Y. Sameshima-Yamashita, T. Yarimiza, and H. Kitamoto, 2015, Contribution of soil esterase to biodegradation of aliphatic polyester agricultural mulch film in cultivated soils, AMB Express, 5 : 10.

\section{Volume 5 Issue 3, March 2016}




\section{Author Profile}

Dr.(Mrs.) J.Kasthuri, M.Sc., Ph.D., has completed 3 Major Research Projects Funded the by University Grants Commission - New Delhi, Ministry of Environment and Forestry - Govt. of India, New Delhi and the Department of Scientific Industrial Research, The Ministry of Science and Technology Govt. of India, New Delhi and One Major Research Project Sponsored by the Management ANJA College, Sivakasi. Besides, the Author has also received grants from CSIR (5), ICMR, UGC (SERO), TNSCST (3), BRNS (2) \& ICAR to conduct 12 Sponsored Workshops / Symposia / Training Programmes.

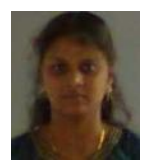

Ms. S. Poornima M.Sc., M.Phil, in Biotechnology, has 10 publications in peer reviewed High Impact Factor Journals. The Author has also very recently submitted her Ph. D., Thesis on Biopolymers Under the Research Guide, Dr.(Mrs.) J.Kasthuri, to Madurai Kamaraj University, Madurai 